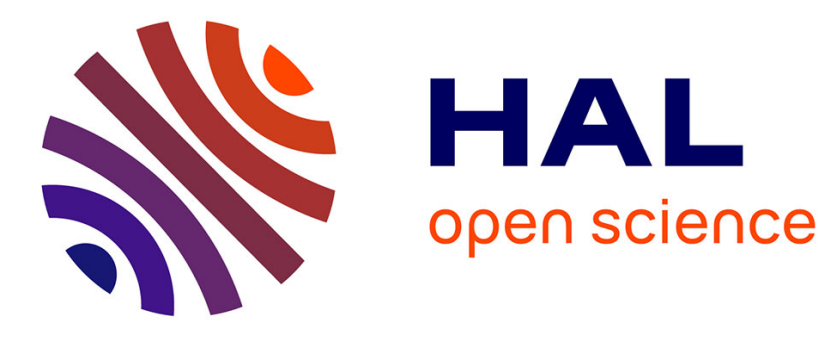

\title{
Stimuli-Responsive Polymer Coatings
}

Fabrice Ofridam, Mohamad Tarhini, Waisudin Badri, Wei Liao, Noureddine

Lebaz, E. Gagnière, Denis Mangin, Emilie Dumas, Sami Ghnimi, Adem

Gharsallaoui, et al.

\section{- To cite this version:}

Fabrice Ofridam, Mohamad Tarhini, Waisudin Badri, Wei Liao, Noureddine Lebaz, et al.. StimuliResponsive Polymer Coatings. Mavinkere Rangappa S., Parameswaranpillai J., Siengchin S. (Eds). Polymer Coatings: Technologies and Applications, CRC Press, pp.199-225, 2021, 9780367189211. hal-02969007

\section{HAL Id: hal-02969007 https://hal.science/hal-02969007}

Submitted on 28 Oct 2021

HAL is a multi-disciplinary open access archive for the deposit and dissemination of scientific research documents, whether they are published or not. The documents may come from teaching and research institutions in France or abroad, or from public or private research centers.
L'archive ouverte pluridisciplinaire HAL, est destinée au dépôt et à la diffusion de documents scientifiques de niveau recherche, publiés ou non, émanant des établissements d'enseignement et de recherche français ou étrangers, des laboratoires publics ou privés. 
Book on: "Polymer Coatings: Technologies and Applications"

Ref No: 297253

Eds: Dr.JyotishkumarParameswaranpillai (Thailand), Dr. Sanjay MavinkereRangappa (Thailand), Dr.SuchartSiengchin (Thailand).

Publisher: CRC Press

\title{
Chapter-11: Stimuli-responsive polymers coatings
}

Fabrice Ofridam ${ }^{1}$,Mohamad Tarhini ${ }^{1}$, Waisudin Badri ${ }^{1}$, Wei Liao ${ }^{1}$, Noureddine Lebaz ${ }^{1}$, Émilie Gagnière ${ }^{1}$, Denis Mangin ${ }^{1}$, Emilie Dumas ${ }^{1}$, Sami Ghnimi, ${ }^{1}$ Adem Gharsallaoui ${ }^{1}$, Abdelhamid Errachid ${ }^{2}$, Hatem Fessi ${ }^{1}$, Abdelhamid Elaissari ${ }^{1}$

1) Univ Lyon, University Claude Bernard Lyon-1, CNRS, LAGEP-UMR 5007, F-69622 Lyon, France

2)Univ Lyon, University Claude Bernard Lyon-1, CNRS, ISA- UMR 5280, CNRS, F-69100 Villeurbanne, France.

\begin{abstract}
Stimuli-responsive polymers are an important branch of polymer science. Their ability to react to external stimuli in a reversible manner makes them a tempting target in several applications. By responding to stimuli such as $\mathrm{pH}$, light, biological elements, temperature, and electricity, these polymers can be used as coating layers for different types of materials in order to add more flexible properties. The use of stimuli-responsive polymers was exploited in food industry, agriculture, biomedical, cosmetic, drug delivery, textile, and many more. In this chapter, some of the most important stimuli-responsive polymers were discussed, and their recent applications in several fields were highlighted.
\end{abstract}




\section{Outline}

1. Introduction

2. Stimuli responsive materials

2.1. Stimuli-responsive polymers

2.2.Stimuli-responsive nanogels

2.3.Stimuli-responsive membrane

3. Stimuli-responsive polymers in coatings technology

3.1.pH- sensitive

3.2.Temperature-sensitive

3.3.Light-sensitive

3.4.Biological environment sensitive

3.5. Electrical sensitive

4. Applications of Stimuli-responsive materials

4.1. Food

4.2. Agricultural

4.3. In vitro biomedical diagnostics

4.4.Sensors

4.5.Drug delivery

4.6. Cosmetic

4.7.Textile

5. Conclusion

6. References 


\section{Introduction}

Polymers are used in most of the goods within our daily life and are even formed important parts of our own body such as DNA and proteins. Since long time, polymers have been used in order to improve the quality of life. However, the real nature of the polymeric materials (natural rubber) was not known. Thanks to the economic dynamism of rubber industry in $19^{\text {th }}$ and $20^{\text {th }}$ century, more investments were taken place to know about rubber behaviour. This event made the intense debate among researchers in this regard. Therefore, they made many efforts and developed certain polymers suitable for almost every imaginable application. This foundational study caused the development of new category of polymers that respond to their environment via changing their physical and chemical properties. Stimuli-responsive polymers are the materials that touch the surroundings or their own state, then can evaluate, and react through altering their functions according to the applied external stimulus. Stimuli-responsive polymers are classified on to the different classes based on the various criteria. For instance, stimuli-responsive polymers are divided on categories of thermal-induced, light-induced, electroresponsive, $\mathrm{pH}$-responsive, and magnetic-responsive polymers (Figure 1). Based on the crosslink's nature, stimuli-responsive polymers are classified into chemically or physically crosslinked. Biodegradable stimuliresponsive polymers are also nominated as a category. According to the switching segments nature, stimuliresponsive polymers are categorized into Tg-type stimuli-responsive polymers with amorphous switching segment and Tm-type stimuli-responsive polymers with crystalline switching segment [1]. Stimuli-responsive polymer coatings continue to be used in evermore increasingly diverse applications and sectors such as: food, agriculture, drug delivery, biomedical diagnostics, sensors, textile and cosmetics [2].

In this chapter, we highlighted some of the structures made from stimuli-responsive materials. We discussed different stimulus mechanisms, and we shed the light on some important application of that technology.

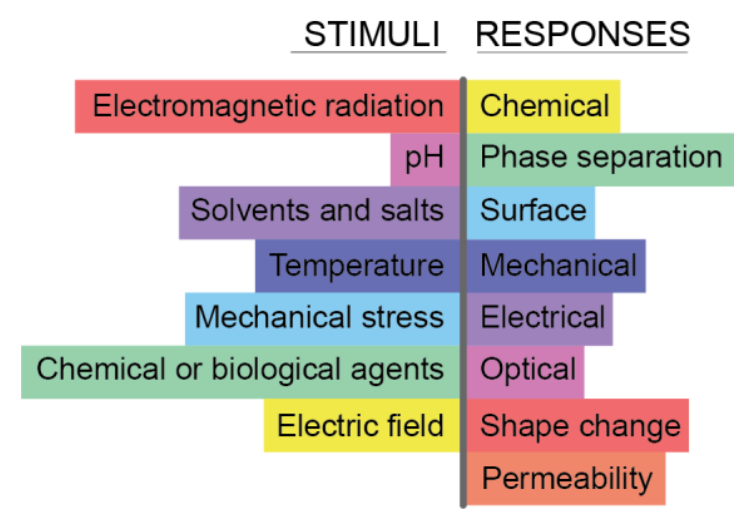

Figure 1: Synthetic polymers possible stimuli and responses

\section{Stimuli responsive materials}

\subsection{Stimuli responsive polymers (SRP)}

Stimuli-responsive polymers, also known as smart or intelligent or environmentally sensitive polymers [3], [4], are materials that constitute today an important class of polymers. They can react to changes in their immediate environment by displaying significant reversible, large, microstructural, physiological and physicochemical changes in their properties, in response to small external changes [5], [6]. One of their fundamental characteristics is that they return to their initial state as soon as the stimuli responsible of their physicochemical properties' modification is removed [7].

Stimuli-responsive polymers can be either from natural or synthetic origin. Among natural responsive polymers, chitosan and albumin are capable to show thermo and pH responsive properties. Moreover, methylcellulose and gelatin can be mentioned with thermo-responsive properties [11]. Synthetic stimuli-responsive systems containing polymers can be designed either with a responsive polymer, or by combining a polymer with a responsive compound, the polymer serving only as a template/carrier for that compound [12]. The synthesis of 
stimuli-responsive polymers calls for polymerization techniques that have been developed and include living anionic and cationic polymerization, controlled radical polymerization, atom transfer radical polymerization, reversible addition fragmentation chain transfer polymerization. In the build-up of synthetic stimuli-responsive polymers, functional groups that make effective response to stimuli (charge, polarity and solvency for instance) are incorporated along a polymer backbone [14], resulting in abrupt and clear changes in macroscopic material properties. Response to stimuli can be defined in various ways. These responses may be associated with modifications in individual polymer chain dimensions or size, changing in shape, surface characteristics, secondary structure, solubility, intermolecular association degree. In most cases, the formation or destruction of secondary forces (hydrogen bonding, hydrophobic effects, electrostatic interactions, etc.), simple reactions (e.g., acid-base reactions) of moieties linked to the polymer backbone, and/or osmotic pressure differences are responsible for this response. Dramatic alterations in the polymeric structure, such as degradation of polymers upon the application of a specific stimulus by bond breakage in the polymer backbone or at pendant cross-linking groups can also be mentioned as response of a stimuli-sensitive polymer to stimuli [15].

External stimuli that provoke these changes can be divided into three main groups: physical stimuli (mechanical stress, electric, magnetic, ultrasounds, light, temperature), chemical stimuli (electrochemical, $\mathrm{pH}$, ionic strength) and biological stimuli (enzyme, biomolecules) [16], [17]. Dual stimuli-responsive polymers can be also mentioned as polymers that simultaneously respond to more than one stimulus. It should take into consideration that stimuli may also occur internally. The well-known examples of this case, which applied in drug delivery systems are including changes in $\mathrm{pH}$ that occur in certain organs or diseased states, change in temperature, presence of specific enzymes, antigens in the human body [18] or changes in physiological conditions [19], [20].

Based on their physical properties, stimuli-responsive polymers are classified into three categories:

- linear free polymer chains in solution: they respond to stimuli that induce a reduction in the number of hydrogen bonds between polymer and water or the neutralization of electrical charges, linear free soluble polymers chains precipitate with the increasing hydrophobicity. Polymers exhibiting this property have applications in proteins, cells and other bioparticles bio-separation

- $\quad$ covalently cross-linked reversible and physical gels: hydrogels that swell in aqueous media may respond rapidly to small changes in $\mathrm{pH}$, temperature, light intensity, ionic strength, magnetism, inflammation, ultrasound, electrical fields or biochemicals. Smart polymers hydrogels find application in microfluidics and actuators, sensors.

- $\quad$ smart surfaces or membranes: polymer chains that have the ability to undergo changes under specific stimuli conditions when adsorbed or grafted to surfaces can make these latest receptive to their own changes. Indeed, the surfaces can be converted from hydrophilic to hydrophobic as well. Thus, surface is hydrophilic when the polymer is in its soluble state and hydrophobic when insoluble resulting from the action of stimuli. Separation of substances that interact differently with hydrophobic matrix can be mentioned as potential application. Smart surfaces find applications in tissue engineering (generation/repair), temperature controlled or in porosity controlled separation [18]-[21].

The rise in interest that has characterized stimuli-responsive polymers in these last decades is related to the various possibilities brought to polymer science and the different promising applications associated. In fact, in addition to the applications evoked above, stimuli-responsive polymers are used in drug delivery [22], [23] smart coating, intelligent medical instruments and auxiliaries, artificial muscles and robotics [13], smart textiles and apparel [24], [25], biomimetic devices and electrochemical devices, microelectromechanical systems. Furthermore, SRP coating was used to fabricate structured particles that can range from nano to micro scale. By adding this responsive layer, particles can undergo modification in their structure, dimensions, and interactions, when introduced to an external stimulus. Several structured particles can be synthetized in this fashion such as core-shell particles, micro/nanospheres, micor/nanogels and nanocomposites (Figure 2) and can be used in various technical and biomedical applications. In fact, using such technology, mimicking a living cell can theoretically being done by combining several compartments that can communicate, exchange energy, and perform mechanical work in a single particulate structure [26]. 


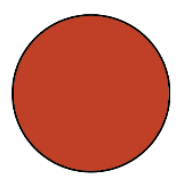

Hard sphere

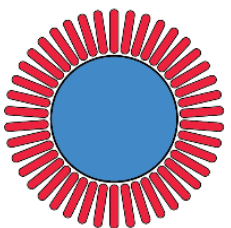

Core-shell

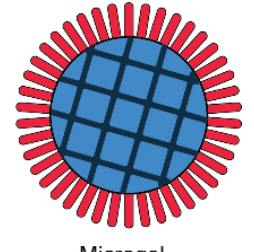

Microgel

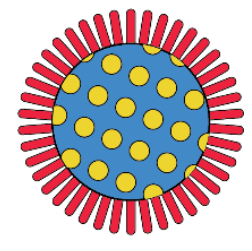

Composite

Figure 2: Some of particulated morphologies

\subsection{Stimuli responsive nanogels}

Polymer nanogels are a special kind of nanomaterials since they combine the properties of nanoparticles and hydrogels. Basically, polymer nanogel are crosslinked colloidal particles formulated by swelling caused by the adsorption of large amounts of solvent. As a result, polymer nanogels are soft nanoparticles thanks to the fluctuation of the high solvent content. However, their crosslinked three-dimensional polymeric network renders these particles resistant to dissolution [27], [28]. Different materials were used to prepare polymer nanogels such as poly( $\mathrm{N}$-isopropylacrylamide), polyethylene glycol, polypeptide, chitosan, etc. [29].

The properties of stimuli-responsive nanogels (SRN) make them a good candidate for biomedical and drug delivery applications. Mainly, being sensitive to environmental stimuli, allows a better control of drug release. In addition, due to their interior crosslinked network, drug loading is much higher and drug leakage is much lower in the case of nanogels comparing to other nanocarriers [30]. Moreover, polymer nanogels possess a stable 3D structure promoting a stable desired size that is needed for passive drug delivery through the enhancement of permeation and retention effect. SRN were also used for tumor active targeting due to their ease of functionalization of polymer units [31]. Additionally, SRN can encapsulate multiple drugs with different solubility profile. Jin et al. were able to develop a triple-responsive (protease/redox/pH) biodegradable PEGylated P(MAA/BACy) nanogels as carrier for both hydrophilic doxorubicin and hydrophobic paclitaxel [32]. It was found that the double loaded system possess favourable targeting ability and therapeutic effect, lower biotoxicity and longer in vivo circulation time, enhanced drug release profile, and a safe biodegradation [33]. These results show the validity of complex nanogels structures as drug vehicles. In fact, core-shell nanogel structure with constrained swelling to one layer was also suggested as a strategy to control multidrug loading with desired amounts [34].

SRN are also known for its ease of synthesis. Basically, two main approaches can be used for the preparation of SRN (Self-assembly of polymers, or polymerization in a heterogeneous environment). In both cases, crosslinking is an important step to ensure the colloidal stability of the nanogels. The polymerization method is usually done by emulsion polymerization, or inverse emulsion polymerization depending on the chosen continuous phase [31]. PEO-block-P(Oligo(ethylene glycol) monomethyl ether methacrylate) particles were synthesized by atom transfer radical polymerization and crosslinked via inverse miniemulsion using a disulfide functionalized crosslinker. The crosslinked nanogels showed excellent colloidal stability and controllable swelling ration [35]. On the other hand, self-assembly of polymers is based on the formation of micelles followed by a non-covalent interaction between the chains and crosslinking [36]. Cholesterol-bearing xyloglucan molecules were selfassembled in water forming nanogels. Cholesterol was used as a physical crosslinking point. It was found that the obtained nanogel can successfully be coupled with hydrophobic molecules with low molecular weight, and by incorporating galactose into their surface, they can be specifically internalized into hepatocytes. Making them a good drug carrier candidates [37]. As stated before, crosslinking is a crucial step in the preparation of SRN. 
Different types of crosslinking can be used such as physical crosslinking, in which interaction between polymer moieties is done through different driving forces: hydrophobic interactions [37], electrostatic interactions, and host-guest interactions [38]. Other crosslinking strategies are disulfide based, amine based, click chemistry based, and photo induced crosslinking [31].

\subsection{Stimuli responsive membranes}

Nowadays, membrane technology has been widely used in numerous applications as drug delivery system [39], chemical separations [40] and water desalination [41], due to its remarkable properties with less energy consumption. Specifically, Stimuli-Responsive Membrane (SRM) has gained much attention in the past decades due to the fact that it could change their physicochemical properties in response to change in the environment stimuli [42]. SRM could be potentially designed to a system, which respond to changes in external stimuli: $\mathrm{pH}$, temperature, ionic strength, light electric or magnetic field [40]. Functional materials (such as polymers, nanogel and nanoparticle) with reversibly switchable physicochemical are generally considered as crucial resources for the preparation of SRM to provide different responsive properties. Husson, et al. [43] had used a two-step process to well explain the responsive mechanisms of SRM. Firstly, changes in the external environment cause a specific-conformation transition of a responsive functional material, and then these conformational transitions to some extent are easy to detect through naked eye or other simple technology methods. In fact, they always react to environmental stimuli in some extent by changing their conformation/polarity along the backbone, side chains, segments or end groups. As a result, alteration of polymer chain length, chemical composition, architecture and topography were conventional methods to optimize the responsive properties of SRM. There are two essential methods used to prepare SRM: (i) blending of different stimuli-responsive polymers to manufacture membranes and (ii) modification of existing membranes through grafting of stimuli-responsive polymers [44]. The former is a crucial method in the design of SRM with porous. By taking this approach, the targeted mechanical properties, pore structure (porosity, pore size and pore-size distribution), and barrier structure (symmetric and asymmetric) can be obtained. Various Membrane processing techniques, such as solvent casting, phase inversion, interpenetrating polymer networks and so on, have been applied to develop SRM. Modification of existing membranes is also important to prepare SRM to enhance membrane performance through functional materials. This method enables responsive properties on the membrane surface and keeps the useful properties of the original membrane. Numerous polymer coating techniques, namely physical adsorption, chemical grafting, coating, layer-by-layer (LBL) assembly, chemical vapor deposition, and so on, have been used to modify the chemical surface or pores of membrane [45].

\section{Stimuli responsive polymers in coating technology}

\section{1. $\mathrm{pH}$ sensitive}

$\mathrm{pH}$-sensitive polymers are a group of stimuli-responsive polymers that can respond to environment $\mathrm{pH}$ throughout structural and property changes such as surface activity, chain, conformation, solubility and configuration [46]. Materials referred to as $\mathrm{pH}$-responsive polymers present the property to have potential ionizable groups in their structure. These groups are weak acidic or basic moieties sensible to $\mathrm{pH}$ variations and conferred the $\mathrm{pH}$ sensitivity to the overall molecule [4]. Sensitivity to $\mathrm{pH}$ in response to environmental $\mathrm{pH}$ modification is made through the acceptance or the release of protons leading to conformational changes and changes in the colloidal behaviour of the polymer such as flocculation, chain collapse-extension, precipitation for homopolymers [46], [47]. pH responsive polymers can be produced by using different polymerization techniques. Emulsion polymerization is the technique used for most of $\mathrm{pH}$ responsive polymers due to the wellcontrolled size distribution. Moreover, anionic polymerization, group transfer polymerization, stable free radical polymerization, atom transfer radical polymerization, atom transfer radical polymerization and reversible addition fragmentation chain transfer polymerization are other polymerization techniques used for the preparation of $\mathrm{pH}$-responsive polymers [48].

According to their origin, natural $\mathrm{pH}$ responsive polymers can be distinguished from synthetic ones. Among natural $\mathrm{pH}$ responsive polymers, the most studied and used ones are Dextran, gelatin, albumin, chitosan, hyaluronic acid, alginic acid [11]. For synthetic pH responsive polymers, two main categories can be identified: polymers with acidic group and polymers with basic group. Table 1 resumes some of the basic polymers used as $\mathrm{pH}$-sensitive polymers or moieties in the build-up of what is known as block pH sensitive polymers.

Indeed, according to their structure, $\mathrm{pH}$-sensitive polymers can be classified as linear homopolymer, copolymer (hydrophilic or amphiphilic block (di, tri, multi block-copolymers), pH-responsive star polymers (with linear 
polymer chains connected to a central core), $\mathrm{pH}$ responsive branched and hyperbranched polymers, $\mathrm{pH}$ responsive dendrimer polymers, $\mathrm{pH}$-responsive brush and comb polymers [46].

Development of performant techniques has allowed the preparation of well-defined block copolymers that exhibit self-assemblage behaviour to external $\mathrm{pH}$ modification. $\mathrm{pH}$ responsive block polymers can exhibit different sorts of responses following a pH modification. Thus, self-assembly such as formation of micelles, unimers, gels, vesicles, swelling, deswelling can be noticed in the case of block copolymer [49], [50].

$\mathrm{pH}$ responsive polymers find application mainly in drug delivery since they are used as a coating material for controlled drug release systems or as drug carriers. Changes in $\mathrm{pH}$ in the gastrointestinal tract (acidic in stomach and basic in intestine) [18] and their biocompatibility as well made $\mathrm{pH}$ sensitive polymers ideal candidates for specific human drug delivery since they are able to switch from swelling to deswelling state in response to local body $\mathrm{pH}$. By this process, they are capable of retaining or release drugs in specific sites or organs according to $\mathrm{pH}$. For this purpose, polymethacrylate, synthetic anionic or cationic copolymers of acrylic acid, methacrylic acid, dimethyl-amino-ethyl methacrylate, methacrylic acid esters are known under the commercial name of Eudragit that are largely used as a coating material for the encapsulation of active ingredients and deliverance in specific site of human body [51]. Moreover, $\mathrm{pH}$ responsive polymer find application in gene delivery and also used in drug delivery to cancer tissues towards micelles' encapsulation using $\mathrm{pH}$ differences between extracellular $\mathrm{pH}$ of normal tissues and tumor extracellular $\mathrm{pH}$ [52]-[54].

Table 1: Classification of basic acidic and basic pH responsive polymers [46]

\begin{tabular}{|c|c|c|}
\hline \multirow{18}{*}{ 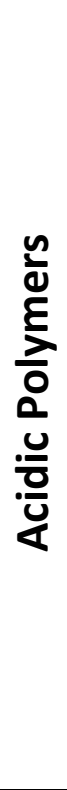 } & \multirow{5}{*}{ Polycarboxylic acids } & Polyacrylic acid PAAc \\
\hline & & Polymethacrylic acid PMMAc \\
\hline & & Polypropylacrylic acid PPAAc \\
\hline & & Poly(4-vinylbenzoic acid) PVBA \\
\hline & & Poly(itaconic acid) PIA \\
\hline & \multirow{4}{*}{ Polyphosphoric acids } & Poly(ethylene glycol acrylate phosphate) PEGAP \\
\hline & & Poly(vinylphosphonic acid) PVPA \\
\hline & & Poly(ethylene glycol methacrylate phosphate) PEGMP \\
\hline & & Poly(4-vinyl-benzyl phosphonic acid) PVBPA \\
\hline & \multirow{4}{*}{ Polysulfonic acids } & Poly(vinylsulfonic acid) PVSA \\
\hline & & Poly(4-styrenesulfonic acid) PSSA \\
\hline & & Poly(2-acrylamido-2-methylpropane sulfonate acid) PAMPS \\
\hline & & Poly(2-acrylamido-3-sulfopropylmethacrylate potassium salt) PKSPMA \\
\hline & \multirow{3}{*}{ Polyaminoacids } & Poly (aspartic acid) PASA \\
\hline & & Poly(L-glutamic acid) PLGA \\
\hline & & Poly(histidine) PHIS \\
\hline & \multirow{2}{*}{ Polyboronic acids } & Poly(vinylphenyl boronic acid)PVPBA \\
\hline & & Poly(3-acrylamidophenyl boronic acid)PAAPBA \\
\hline \multirow{14}{*}{ 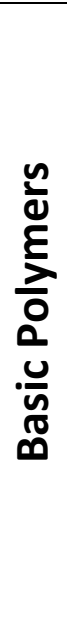 } & \multirow{9}{*}{$\begin{array}{l}\text { Tertiary amine } \\
\text { polymers }\end{array}$} & Poly(2-dimethylamino)ethyl methacrylate PDMA \\
\hline & & Poly(2-diethylamino) ethyl methacrylate PDEA \\
\hline & & Poly(2-dipropylamino) ethyl methacrylate PDPAEMA \\
\hline & & Poly(2-diisopropylamino) ethyl methacrylate PDPA \\
\hline & & Poly(N-(3-dimethylamino)-propyl) methacrylamide PDMAPMAm \\
\hline & & Poly((2-dimethylamino)ethyl acrylate)PDMAEA \\
\hline & & Poly (2-ter-butylamino)ethyl methacrylate PtBAEMA \\
\hline & & Poly(N,N-dialkylvinylbenzylamine) \\
\hline & & Poly(2-diethylamino)ethyl acrylamide PDEAm \\
\hline & \multirow{5}{*}{$\begin{array}{l}\text { Morpholino, } \\
\text { pyrrolidineand } \\
\text { piperazine polymers }\end{array}$} & Poly(2-N-morpholino)ethyl methacrylate PMEMA \\
\hline & & Polyacrylomorpholine PAM \\
\hline & & Poly(2-N-morpholino)ethylmethacrylamide PMEMAm \\
\hline & & Poly(N-ethylpyrrolidine methacrylate) PEPyM \\
\hline & & Poly(N-acrylo-N'-alkenyl piperazine) \\
\hline
\end{tabular}




\begin{tabular}{|l|l|l|}
\hline \multirow{4}{*}{$\begin{array}{l}\text { Pyridine and imidazole } \\
\text { polymers }\end{array}$} & Poly(4-vinylpyridine) P4VP \\
\cline { 3 - 3 } & Poly(2-vinylpyridine) P2VP \\
\cline { 2 - 3 } & Poly(N-vinylimidazole) PVI \\
\cline { 2 - 3 } & Poly(6-(1-H-imidazol-1-yl)hexyl-methacrylate PImHeMA \\
\hline \multirow{2}{*}{ Dendrimers } & Poly(propylenimine) dendrimer PPI \\
\cline { 3 - 3 } & Polyethylenimine dendrimer PEI \\
\cline { 2 - 3 } & Poly(amidoamine) dendrimer PAMAM \\
\hline
\end{tabular}

\subsection{Light-sensitive}

Light-responsive polymers are photo deformable in response to light stimuli. The advantage of using such materials in coating technology lies in the simplicity of operation, the avoidance of using chemical reactants and therefore limiting chemical contamination, and scalable miniaturization [55]. In addition, light sensitivity offer a remote application, ease of dosing, and accurate positioning and resolution of the response [56].

For a polymer to become light-responsive, a chromophore (photo-response functional group) should be incorporated into the polymer chain. Two categories of chromophore can be found, reversible and irreversible. Reversible chromophore, upon light excitation at a specific wavelength, undertake a reversible isomerization. This allows the alteration of the properties of the host polymer by irradiation a two different wavelength. This reversible isomerization is important in different applications such as information storage and artificial muscles [57], [58]. Spiropyrans, an organic molecule that's upon light excitation engaged in a photocleavage of a sprio CO bond, was used to prepare photochromic polymer brushes. Dense and smooth polymer films were successfully prepared and used as surfaces with switchable color and wettability by light stimulation. Using a specific wavelength, the nonpolar spiropyran can become polar, and revert to its nonpolar state using visible light [59].

On the other hand, irreversible chromophore is subject to unreversed changes upon light excitation. Therefore, equilibrium between two states does not exist. This will give the advantage of $100 \%$ photo-conversion, which make them ideal for drug delivery since this irreversibility can lead to effective drug release, and better degradation when required [56]. This strategy was used in Laser Induced Forward Transfer method (LIFT), in which biological molecules such as protein and DNA, and even living organisms (cells) can be coated with a sacrificial polymer layer, and upon laser pulse emission, the carried molecule can be shifted from the polymer substrate to a receiver substrate in close proximity [60]. Doraiswamy et al. were able to transfer mammalian cells using polytriazenes as sacrificial polymer that also acts as irreversible chromophore [61]. Another approach was the coating of silica nanoparticles with NIR-light responsive polymer via self-assembly. Due to the presence of coumarin moieties in the polymer, it can be disrupted by excitation by a femtosecond NIR light laser $(800 \mathrm{~nm})$ via a two-photon absorption process. It was found that under excitation with such light, the core-shell structure of the nonvehicle was able to release the pre-loaded drug in a controllable manner. In addition, in-vitro results shows a successful targeting of tumor cells once decorated with folic acid [62]. NIR range is considered more desirable for drug delivery than UV or visible light since it offers deep penetration without harming body tissues, however, most of the light-sensitive systems were tested in-vitro while in-vivo applications still requires further development.

\subsection{Biological environment sensitive}

Smart polymers that respond to physical and chemical stimuli such as light, $\mathrm{pH}$, or temperature are desired because they are well controlled and easily measured. These polymers can be stimulated externally, offering a good control of the material properties. However, when it comes to biological systems, it is more complex and challenging. A temperature responsive polymer for example cannot be targeted toward a specific receiver. Therefore, a more targeted responsive systems are necessary [63].

Polymer responsive to biological environment are used for living organisms and applied in drug delivery, biomedicine, and cell engineering [64]. They can be enzyme-responsive, ligand-responsive, cell-responsive, or generally responsive to biochemical environments. For example, responsiveness to reactive oxygen species (ROS) at the inflammation site of tumors can be exploited for targeted drug delivery by drug-loaded responsive polymer nanoparticles [65]. Doxorubicin-loaded ROS-responsive polymeric micelles were developed by Sun et al. as antitumor agents by introducing ROS responsive thioketal as a linker between poly(ethylene glycol) and poly( $\varepsilon$-caprolactone). In a ROS rich environment, the surface of these micelles is degraded and the drug was 
specifically released allowing a better in-vitro anticancer activity of doxorubicin [66]. Other ROS responsive moieties were used for such applications such as boronic ester and sulfide groups. However, few challenges still exist. The levels of ROS can vary from patient to another and therefore these formulations must be personalized for each case. In addition, the biocompatibility of the used linkers, and their stability during circulation and in normal cell environment should be more addressed [67].

Enzyme-responsive polymers are another promising approach. These polymers have the advantages of being biocompatible, since enzymatic stimuli occurs naturally, and lead to more accurate targeting for the dug, and therefore lead to higher therapeutic efficiency and lower side effects [63]. Due to these advantages, enzyme responsive polymers were applied as cell supports, injectable scaffolds, and drug delivery systems. Huang et al. used casein (a natural milk protein) as a coat for iron oxide nanoparticles. This system was loaded with doxorubicin as a model drug. It was found that these particles were stable in the acidic gastric environment in the presence of gastric protease. However, the outer casein layer was degraded in the presence of intestinal protease. Allowing the maintenance of the drug's bioactivity, and the enhancement of the drug delivery efficiency [68]. Synthetic polymers can also be used as enzyme-responsive drug delivery systems by introducing an enzyme-sensitive crosslinker to their matrix, rendering the polymeric structure a target to degradation by protease. Poly-styrene nanoparticles were prepared by inverse miniemulsion and crosslinked with a hydrophobic peptide as a trypsin substrate. This formulation can have a promising future in nanomedicine, invitro detection of specific enzymes, and cancer therapy [69]. Another approach of enzyme-responsiveness is nanoparticles sensitive to protein kinase. Nanoparticles comprising hydrophobically modified peptide substrate of protein kinase were prepared for monitoring the activity of the latter by exploiting the enzyme to change the electrostatic interaction of the polymer aggregates in the particle [70].

Biological environment-responsive polymers were also applied as smart coatings for textiles developed as antibacterial vectors and used in several applications such as bedding and wound dressing. Kratochvil et al. developed a non-woven polymer nanofiber coating loaded with macrocyclic peptide 1, a potent non-bactericidal quorum sensing inhibitor in S. aureus. The peptide was loaded to the nanofiber by electrospinning, and was able to inhibit the production of bacterial hemolysins, a quorum sensing controlled virulence phenotype, and reduce the lysis of erythrocytes [71]. The release of antimicrobial agent was in response to pathogenic bacteria specifically and not responding to nonpathogenic strains. This approach can be a great alternative to antibioticdependent therapy especially with the growing antibiotic resistance of $S$. aureus [72].

\subsection{Temperature sensitive}

Temperature-sensitive polymers (TSP) are sensitive to the temperature and alter their microstructural characteristics in response to temperature degree change. Temperature-sensitive polymers are well known and the most employed polymers in drug delivery and biomaterials. Indeed, small change in temperature is able to make new adjustments in TPS because they have very sensitive balance between the hydrophobic and hydrophilic groups [73]. The critical solution temperature is an important property of such kind of polymers. The polymer will become insoluble after heating, if the polymer solution has a phase lower than critical solution temperature, i.e., it has one lower critical solution temperature (LCST). The interaction strengths (hydrogen linkages) between the polymer and water molecules become inconvenient above the critical solution temperature that cause polymer swelling because of its dehydration and occurrence of hydrophobic interaction predominance [74].

The LSCT is the critical temperature where the polymeric solution separates into two phases, going from one phase (isotropic state) to two phases (anisotropic state). LCST change due to hydrophilic or hydrophobic incorporation existence within a polymeric system. The phase transition occurrence that causes a change in polymer is easily observable in certain temperatures.

TSP were mainly used in biomedical applications where the selected TSP should be biocompatible and nonimmunogenic. To design an effective platform, it is crucial to understand the molecular mechanism behind the performance of TSP [75]. 


\subsection{Electrical sensitive}

Electrical responsive polymers have the ability to deform (shrinking, swelling, bending) in response to an external electric field. In other words, they have the ability to transform electrical input into mechanical output. For this reason, electro-responsive polymers found their way to biomechanical application, artificial muscles, sensing, chemical separation, and drug delivery [76].

The most researched form of electro-responsive polymers is polyelectrolyte hydrogels. In the presence of an electrical field, the ionic groups inside the gel get pushed to the anode side, which leads to swelling or the cathode side, which leads to shrinking and ultimately leads to a reversible deformation and volume change of the gel. Neutral polymers can also be affected by electric field; many polymer gels have been found to be a subject of swelling via electrostriction (change in length of materials in the presence of external electric field). In addition, neutral materials can acquire a translational motion when introduced inside a non-uniform electric field via dielectrophoretic effect [77]. Both natural and synthetic polymer was used to prepare electric responsive hydrogel such as chitosan, chondroitin sulfate, hyaluronic acid, allylamine, acrylonitrile, etc.

Electrical sensitive polymers have been studied in the development of artificial muscles. Many polymers were used in that context, but perhaps the most interesting one is polyacrylamide, and this is due to several reasons: it is cheap, easy to manipulate, biocompatible, and have the same properties as living tissues. Moschou et al. developed an artificial muscle material based on acrylic acid/acrylamide hydrogel blended with a conductive polypyrrole/carbon black composite. It was found that under electroactuation with a 1-volt voltage, the material showed a relatively fast response of 5 seconds and reversible bending in a neutral $\mathrm{pH}$. In addition, the artificial muscle was incorporated into a bio-micro-electro-mechanical system by immersing it in a $0.15 \mathrm{M} \mathrm{NaCl}$ solution and place above the poly(dimethyl siloxane) membrane-covered microresevoir. It was found that under electroactuation, the bent hydrogel was able to push the membrane surface and pumps the fluid form the reservoir into a calibrated microchannel with a low power consumption [78].

Electroresponsive polymers were also used in drug delivery. Kagatani et al. were able to produce poly(dimethylaminopropylacrylamide) gel loaded with insulin. This gel was administered subcutaneously in rats, and by stimulation with an external constant current of $1 \mathrm{~mA}$, a pulsatile decrease in plasma glucose level was observed. The release is caused by the electrokinetic flow of dissolved insulin with the water from the gel, explained by electrophoresis of the countrions and electroosmosis of water molecules in the crosslinked polyelectroyte gel network [79].

\section{Application of stimuli-responsive materials}

Due to their reversible responsiveness to environmental stimulus, stimuli responsive polymer coatings were used in several applications. In this part, we will highlight some of these applications, the concept of their using, and recent advancement in their respective field. In addition, some of the recent applications were summarized in Table 2. 


\subsection{Food}

Stimuli-responsive polymer systems have proven to be an efficient tool to use in food packing systems with great potential to improve the safety, quality, and traceability of food products, as well as its convenience for consumers [100]. In addition, stimuli-responsive polymer was used in some functional food as coating materials for particle [101] or emulsion [102].

It is well established food quality control that is an essential research target to protect consumers against foodborne infection and to maximize the benefits of the food industries. Recent development of smart food packaging to monitor the condition changes of food has attracted much attention. This technology may be incorporated in packaging materials or attached to the inside or outside of a package and aims to senses and shares more information of food quality to consumer or producer during transport and storage [103]. Stimuliresponsive polymers have been regarded as a useful method to acquire packaging with responsive properties. For instance, a smart packaging system can use to observe the distinct $\mathrm{pH}$ of foods with visual colorimetric changes of $\mathrm{pH}$-responsive polymers inside the smart package [104]. In addition, packaging with responsive properties includes the sensors, which would detect the temperature, gas formation, microbial growth, freshness and so on [100]. Principally, for food applications, the material for packaging should have the "Generally Regarded As Safe (GRAS)" status. Thus, most of the stimuli-responsive materials that can be used in actual food packaging have very limited implementation. Rather, natural polymers are promising materials in the design of smart packaging due to their compatibility and nontoxic nature on administration. Exploiting the pH-tunable ability of chitosan, Maciel, Yoshida, and Franco [80] established a prototype of a colorimetric temperature indicator for monitoring food quality. Liu, et, al. [81] has developed a simple yet reversible $\mathrm{pH}$ responsive chitosan-based emulsion system by exploiting the $\mathrm{pH}$-tunable ability of chitosan. Based on polyaniline film, Bambang, et, al. [82] developed a novel colorimetric food package label as a chemical sensor for real-time monitoring of the microbial breakdown products in the headspace of packaged fish. Another packaging system from Cryovac Div., Sealed Air Corporation, they developed Cryovac ${ }^{\circledR}$ OS2000 ${ }^{\mathrm{TM}}$ polymer-based oxygen-scavenging film, which have applications in different food products such as smoked meat products and processed meats [83]. On the other hand, polymer sensors, such as combining oxygen and carbon dioxide measurements in a single sensor [105], have been employed to smart packaging systems in many recently developed packaging systems. There are several accepted applications in polymer-based sensors where the ripeness of the pear is determined by detecting volatile aromatic compounds, or the freshness of the fish is determined by monitoring the concentration of volatile amines [106]. Nicolas, et, al. [84] developed a polymeric solid-state $\mathrm{CO} 2$ sensor, which uses phosphorescent Pt-porphyrin for food packaging applications.

The use of stimuli-responsive material in the food packaging industry is a new strategy to get markedly improved packaging properties. However, the topic of using stimuli-responsive polymer to more industries is still a challenge for food application.

\subsection{Agriculture}

Over the past few decades, using more advanced agricultural methods (high-tech machinery, resources, and chemicals) for analyzing or monitoring of soil and crop have been a research trend in agricultural planting to get more information and evaluate their maturity and status health. Among those methods, incorporation of stimuliresponsive polymers as sensors into fertilizers and pesticides to respond to the external environment is promising field for residue analysis of soil and crop [107], [108].

The application of fertilizers and pesticides significantly have great effect for crop productivity, and the major drawback of conventional applications, in general, is the loss depending on the mode of application and weather conditions. Instead, the applications of these chemical products have been expected to transform into smart agrarian practices with more functional properties. As such, it is very interesting to combine fertilizers and pesticides with stimuli-sensitive polymers [109]. The products used in agriculture may get the properties sensitive to $\mathrm{pH}$, light, temperature, biological environment from stimuli-responsive materials, which can be used to formulate respond to surrounding micro-environment intelligently and smartly eliciting a better and controlled release. For instance, Zhiyan et al. established successful development of glutathione-responsive carboxymethyl chitosan systems for controlled release of Diuron herbicide with the pre-emergence treatment of target species (Echinochloa crus-galli) and their results showed it will be a promising candidate for controlled 
release of pesticides in agriculture [85]. Chi et al. [86] developed core/shell attapulgite- $\mathrm{NH}_{4} \mathrm{HCO}_{3}-$ glyphosate/amino silicone oil-poly(vinyl alcohol) (PVA) nanocomposites that offered temperature responsive controlled release of glyphosate herbicide. Another work was done by Liu et al [110], they used modified soybean protein isolate and carboxymethyl cellulose by the hydrazone formation to synthesizing a $\mathrm{pH}$ responsive Avermectin nanoparticle. On the other hand, Hydrogels are cross-linked networks of polymers having high water retention capacity and can be as fertilizer with stimuli-responsive towards temperature, $\mathrm{pH}$, enzymes etc. [87]. Chen et al, [87] fabricated an environmentally responsive cellulose-based hydrogels by hydroxypropyl methylcellulose for a controlled-release water-soluble fertilizer and this study showed it have potential as controlled release devices in horticulture and agriculture. Another study reported that anion-responsive carbon nanosystem prepared by polyethylenimine modified hollow/mesoporous carbon nanoparticles to improve selenium utilization efficiency in vegetables [110].

The presence of stimuli-responsive polymers in fertilizers and pesticides open more chances for many possibilities in the development of modern agriculture. However, despite many positive aspects of blending fertilizers and pesticides with responsive materials, careful evaluation is still required before using these technologies for crops in the future.

\subsection{In vitro biomedical diagnostics}

Hoffman et al; designed a smart polymer-biomolecule conjugate for immunoassay that was based on the conjugation of an antibody to Poly(N-isopropylacrylamide) (PNIPAAm). In order to capture an antigen such as biomarker of hepatitis or AIDS, blood test sample including smart bioconjugate. Consecutively, second labelled antibody was added and that detection antibody was designed to affinity link to the same antigen. At the end to separate the phase labeled immune complex sandwich, solution was warmed. The assay was similar with an Enzyme-Linked Immunosorbent Assay (ELISA), except that it was performed in solution with a last step named phase-separation. This method, in comparison with the typical ELISA multi-well plate assay, was much faster and just as accurate.

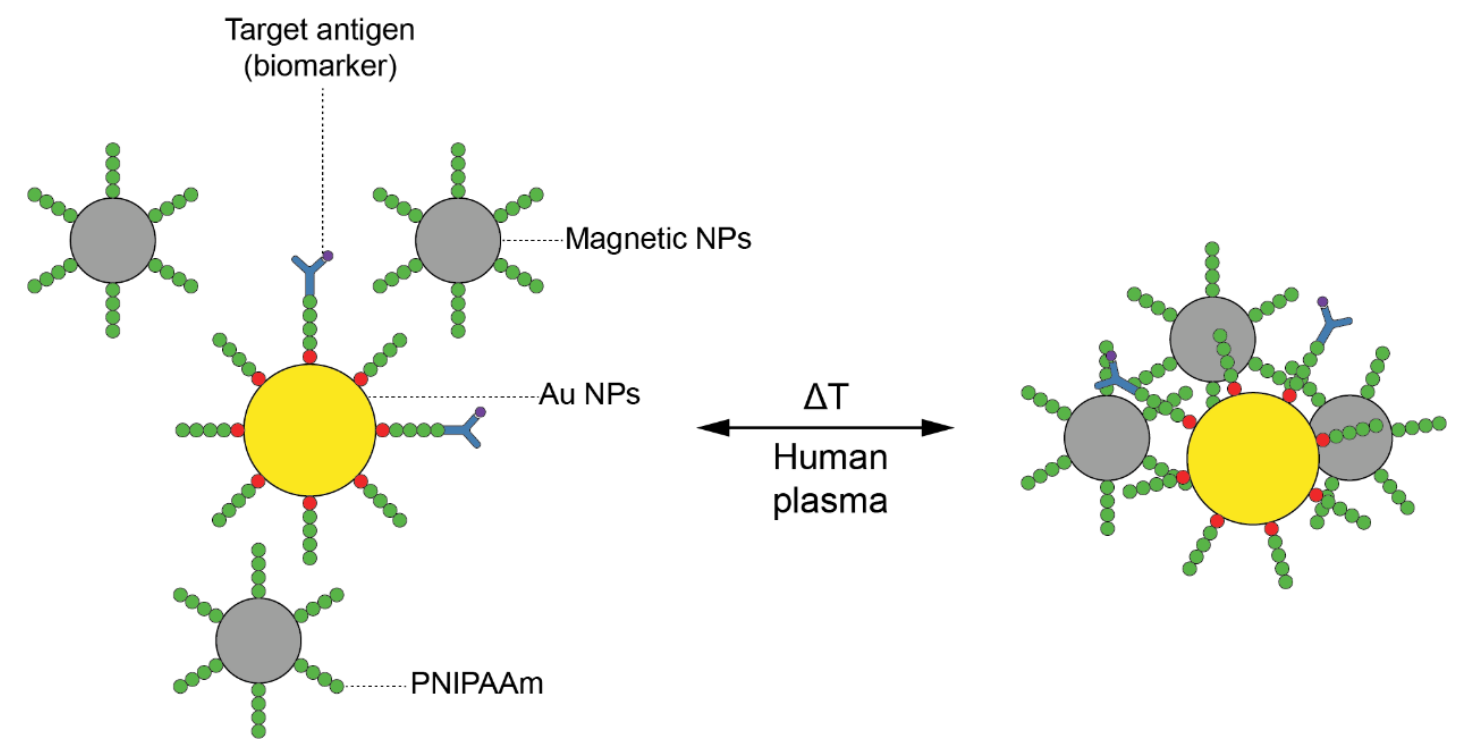

Figure 3: When PNIPAAm is coated on magnetic nanoparticles (mNP) and gold nanoparticles (AuNP), it acts to aggregate or "glue" the NPs together when the temperature is raised above the LCST of PNIPAAm.

Stayton \& Hoffman, et al. recently applied smart PNIPAAm technology to several novel surface and nanoparticlebased diagnostic systems, which use PNIPAAm coatings on microfluidic channels, on gold nanoparticles and on magnetic nanoparticles. These smart nano-scale systems are designing and developed for clinical immunoassays [88]. 


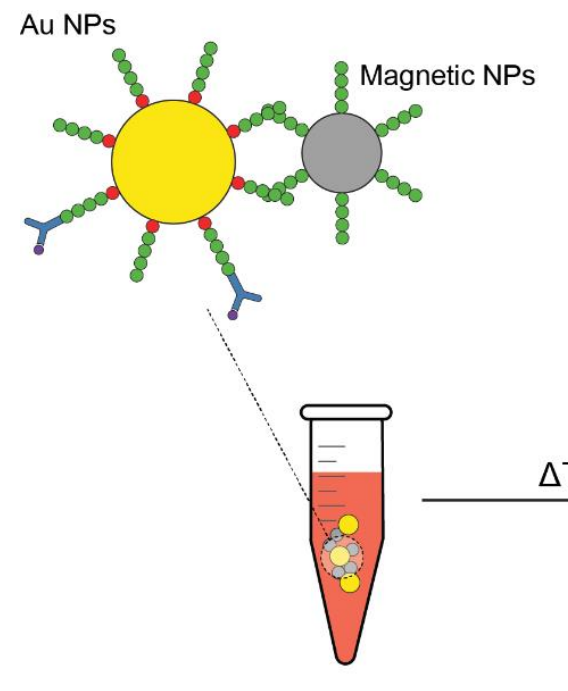

Human plasma

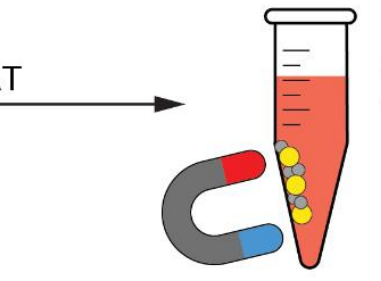

Co-aggregation Magnetic separation

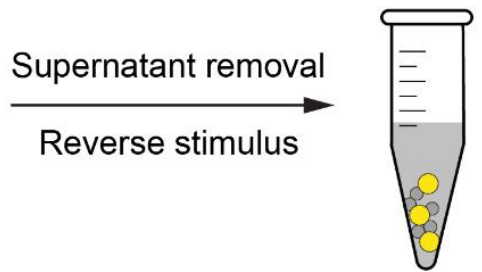

Purified, enriched, and labeled biomarker (half-sandwich)

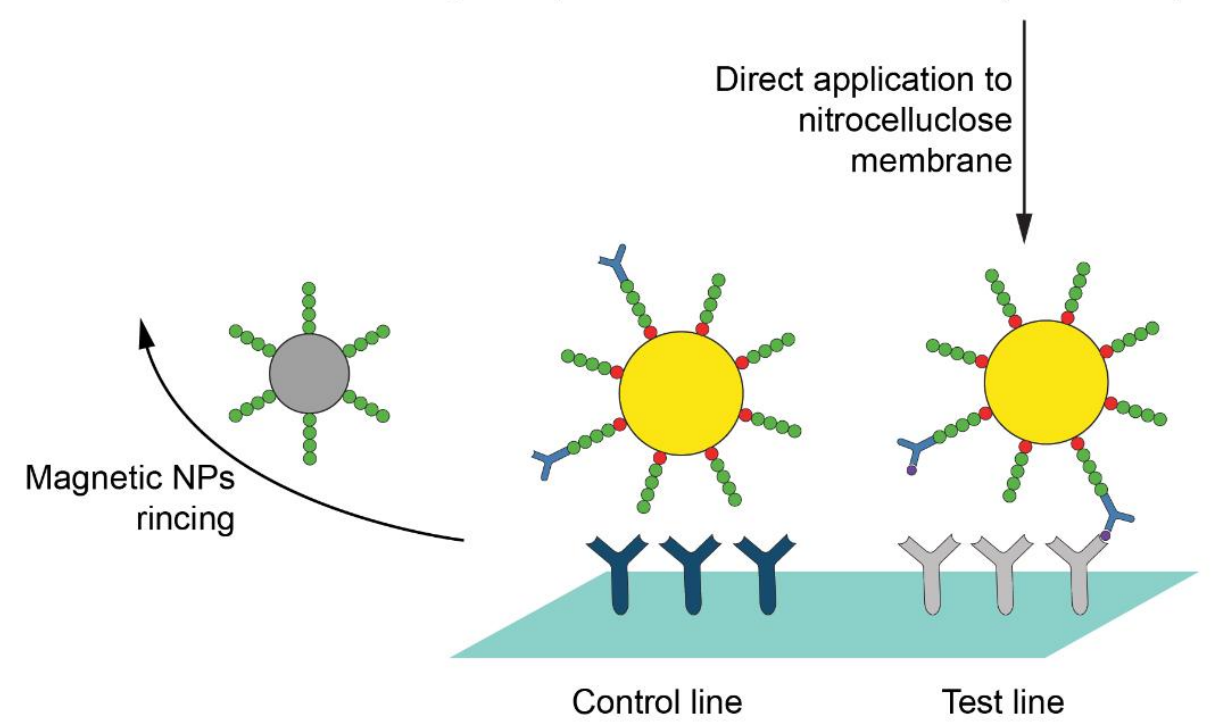

Figure 4: Biomarkers in blood plasma test samples at RT are captured by antibodies bound to PNIPAAm-coated gold nanoparticles (NPs) that are then thermally-aggregated with PNIPAAm-coated magnetic NPs and isolated and concentrated by a magnetic field. After washing the aggregates and then lowering the temperature below the LCST, the NPs are dispersed and flowed onto a lateral flow strip for biomarker assay.

\subsection{Drug delivery}

Due to their properties and flexibility, stimulu-responsive polymers found their way into drug delivery. They were used a nanocarriers, hydrogels, micelles, and complexes that can safely carry and protect the drug through in-vivo circulation and release it in the desired site due to environment change. In addition, SRP were used in drug delivery as coating materials for drug tablets and nanocarriers [111].

Enteric coating or enteric capsule is a polymer layer added to drug tablets to increase the efficiency of the drug by protecting the tablet from early degradation [112]. Two types of enteric coatings are popular. One is based on copolymer of methacrylic monomers and the other is based on ethylcellulose. Both types have a pH sensitive profile. They are hydrophobic at gastric $\mathrm{pH}$ that restrict the release of the drug, and they became hydrophilic at intestinal $\mathrm{pH}$ allowing the drug to be released in the intestines, and therefore, protecting it from; gastric degradation. This will improve the efficiency of oral drug delivery [111]. This characteristic was exploited to deliver peptides and protein through oral route. Mucoadhesive intestinal patches loaded with insulin were coated with ethycellulose to secure a safe passage of a therapeutic dose of insulin through the digestive system 
to be released near intestinal mucosa. In vivo results showed that these patches induced dose-dependent hypoglycemia in normal rats with a maximum drop in blood glucose levels of $75 \%$ [93]. In another study, chitosan and poly( $\gamma$-glutamic acid) $\mathrm{pH}$ sensitive nanoparticles were loaded with insulin, freeze dried, and coated with an Eudragit ${ }^{\circledR}$ S100 and Eudragit ${ }^{\circledR}$ L100-55 capsules. After invivo oral administration in diabetic rats, it was found that intestinal absorption of insulin was enhance, and the relative bioavailability was about 20\% [94]. Light-responsive polymer coating was also used for insulin delivery. Gold nanoparticles loaded with insulin and coated with hydrophobic ethylcellulose were developed. By applying a near-infrared irradiation, gold nanoparticles are heated leading to reversible collapse of the polymer network, resulting in the formation of porous structure, and therefore, allows a rapid diffusion of insulin. It was also found by controlling the irradiation, insulin dosing in diabetic rats can be controlled [95].

Stimuli-responsive polymers were also used as coating materials in the development of core-shell organicinorganic drug nanovehicles. Magnetite nanoparticles were coated with the temperature responsive biopolymer poly(N-isopropylacrylamide-co-N,N-dimethylacrylamide) to form a core-shell structure with a size of $8 \mathrm{~nm}$. Physico-chemical characterization demonstrated the suitability of such system in magnetic drug delivery, and in magnetic resonance imaging by combining the advantages of magnetic nanoparticles and stimuli-responsive polymer [96]. Core-shell nanocarriers were also used for the delivery of anticancer agents. Magnetic core-shell nanoparticles were synthesized using poly- $\mathrm{N}$-isopropylacrylamide-co-itaconic acid containing thiol side groups as a thermo and $\mathrm{pH}$ responsive polymer. Particles were used as a vehicle for doxorubicin with a size of $50 \mathrm{~nm}$ and a high loading capacity (55\%). The $\mathrm{pH}$ and temperature triggered release of doxorubicing at tumor tissue environment was $39 \%$ higher than the physiological conditions. In addition, this carrier shows no cytotoxicity while inducing an efficient anticancer effect in-vitro. Suggesting its suitability as a drug carrier in general and as an anti-cancer agent in specific [97].

SRP coating are, in conclusion, a very promising agent for drug delivery, especially when it comes to oral administration of therapeutic peptides. The topic that is until now remains a challenge for pharmaceutical research.

\subsection{Sensors}

Sensors are devices that can convert an input received from a surrounding variation into an output signal that can be transformed into readable observation. The ability of stimuli responsive polymers to interact with the surrounding environment, make it a good candidate for sensors fabrications. Different stimuli responsive sensors were developed such as temperature, $\mathrm{pH}, \mathrm{CO}_{2}$, and biological induced. Moreover, stimuli responsive polymer coated nanoparticles have gained attention in sensing research to the optical properties of nanoparticles.

Gold nanoparticles coated with poly( $\mathrm{N}$-isopropylacrylamide) were developed as colorimetric temperature and salt sensors. Polymer was synthesized by RAFT polymerization and grafted into the nanoparticles by ligand exchange process. It was found that by increasing temperature, these particles can change color from red to purple to blue due to the electronic coupling of the surface plasma on resonance caused by the aggregation of gold nanoparticles. In addition, it was found that the range of temperature sensitivity increase in the presence of salt due to charge screening [89]. In another study, gold nanoparticles were used to develop $\mathrm{CO}_{2}$ sensors. Poly(N-(3-amidino)-aniline), a $\mathrm{CO}_{2}$ responsive polymer, was grafted on the surface of the particles, and in the presence of dissolved $\mathrm{CO}_{2}$, it can swell and detach from the surface of the particles due to the protonation of its amidine group and the formation of hydrophilic amidinium. This change can lead to the aggregation of the nanoparticles and a change in color. The limit of detection of this sensor was identified at $0.0024 \mathrm{hPa}$ [90]. SRP were also used to produce highly sensitive fiber-optic marine salinity sensors. Long-period gratings were coated with ionic-strength-responsive chitosan ( $\mathrm{CHI}$ )/poly (acrylic acid) polyelectrolyte multilayers by layer-by-layer assembly method. In the presence of $\mathrm{NaCl}$, a shrinkage in the coating layer and salt ion doping occurs leading to an increase in water content and resulting in a light shifting from red to blue. The blue shift increases with the increase of salt concentration. It was also noticed that polymer coated systems have a higher sensitivity than the non-coated ones [91]. 
Biosensing was also a target for SRP. Platinum electrode coated with a polymer-polymer complex of phenyl boronic acid with tertiary amine moieties and poly (vinyl alcohol) (PVA) were developed as glucose level sensors. The system was tested in glucose rich Dulbecco's phosphate buffer saline solution at $\mathrm{pH}$ 7.4. It was found that in the presence of glucose, a change in the swelling of the polymer layer is induced, which leads to an increase in the diffusion of ion species, and thus, increase the measurable current change. This glucose sensor was proven to be of high selectivity and suitable for the physiological concentration of glucose since current changes were proportional to glucose concentration in the range $0-300 \mathrm{mg} / \mathrm{dL}$ [92]. Another glucose sensing strategy was to develop an edible electrochemical biosensor with an important resistance to extreme acidic conditions. The direct and stable glucose monitoring was achieved using edible materials such as olive oil and activated charcoal as carbon-paste biosensors. These materials were able to protect the embedded glucose oxidase enzyme from strong acidic conditions. Moreover, the electrode was coated with $\mathrm{pH}$-responsive enteric coatings (Eudragit ${ }^{\circledR}$ L100 and Eudragit ${ }^{\circledR}$ E PO), which allow the control of the activation at different pHs corresponding to gastric and intestinal conditions [113].

The presence of a high range of biocompatible SRP opens the opportunity for many possibilities in the development of biosensors. However, an improve in selectivity, stability, sensitivity, and output readability is always required [114].

\subsection{Cosmetic}

In general polymers are the second largest category of ingredients in the composition of cosmetics and personal care products. Stimuli-responsive polymers are interesting in the cosmetics because they help formulation of cosmetics to exhibit wanted characteristics in the storage container. Upon the heating (over than threshold temperature) of thermally reversible viscosifying polymers, they show a dramatic viscosity raise in solution viscosity. In the aqueous compositions consisting of polymers possessing a poly (2-acrylamido-2methylpropanesulphonic acid) backbone and grafted chains of polyoxyethylene and polyoxypropylene or polyoxybutylene thermal gelling was observed.

It is possible to use gelation in response to the stimulus such as temperature as a processing aid,or instance, in the case of multiple emulsions preparation. To obtain water/oil/water multiple emulsions normally it is needed for the first time to prepare the internal emulsion in separate way from the external base and afterwards to mix slightly the phases together to prevent internal water-phase escape into the external aqueous phase. Processing complications are raised when the viscosity of the oil-phase is considerably higher than of either of the aqueous phases. According to a research performed by Mercier usage of amphipathic reverse thermal gelling polymers can increase the viscosity of both the internal and external aqueous phase so permit one pot mixing of multiple phase emulsions without breaking the W/O droplets and by that the mixing of the internal aqueous phase and the external aqueous phase is avoided [98].

\subsection{Textile}

In order to bring an added value on functional textiles coating and lamination can be the interesting strategies. Due to the wider application of the functional textiles, the use of these techniques is boosting since coating and lamination extend the range of smart performance properties of textiles. To design fabrics with functional properties, coating and lamination techniques are employed. Furthermore, thanks to the widespread application of coating and lamination over the range of technical textiles sectors, improve functionality and durability. Coating and lamination are including: WVP, waterproofness, increased abrasion, flame, and UV resistance or phase change materials. Usually, coatings (often in liquid form) are applied to fabrics during the preparation stage. The preparation of laminate membrane is needed to laminate that will be applied on the textile consecutively. Coated and laminated textiles widespread application across the different types of technical textile sectors are including antibacterial coatings, waterproof breathable, water vapour and air permeable, UV resistance, phase change materials, etc. [25], [115]. The way of coatings and lamination sticking to the fabric surface determine the method of their communication with the fabric. Since coating as liquid form applied on the fabric that covers its surface and penetrate the fabric structure, filling the air pockets, and bridging the interstices. Occasionally, the end product is defined as a composite that is attributed to the combination of textile and nontextile. The tear strength and thermomechanical properties determine the mechanical properties of the fabric [99], [116], [117]. 
The textile Institutes describes a coated textile as a material composed of two or more layers, at least one of which is a textile fabric and at least one of which is a substantially continuous polymeric layer. This polymeric layer is administered in liquid form with solvent or water base that evaporates off leaving the polymer behind, applied to one or both surfaces. Laminated textile formed from one or more layers of textile and nontextile component. Based on the Textile Institute laminated or combined fabric is a material composed of two or more layers, at least one of which is a textile fabric, bonded closely together by means of an added adhesive, or by the adhesive properties of one or more of the component layers. Smart clothing is employing to keep users warm by default, for example, in winter, and then to help the body spontaneously in order to cool down when the wearer sweats [118].

Table 2: applications of stimuli responsive polymers

\begin{tabular}{|c|c|c|c|c|}
\hline Application & Polymer & Responsivness & Formulation & References \\
\hline \multirow[t]{5}{*}{ Food } & chitosan & $\begin{array}{l}\mathrm{pH} \text { and } \\
\text { temperature }\end{array}$ & $\begin{array}{l}\text { colorimetric } \\
\text { temperature } \\
\text { indicator for } \\
\text { monitoring food } \\
\text { quality }\end{array}$ & {$[80]$} \\
\hline & chitosan & $\mathrm{pH}$ & $\begin{array}{l}\text { chitosan based } \\
\text { emulsion system }\end{array}$ & [81] \\
\hline & polyaniline & $\begin{array}{l}\text { microbial } \\
\text { breakdown } \\
\text { products }\end{array}$ & Films & [82] \\
\hline & polymers & oxygen & $\begin{array}{l}\text { oxygen scavenging } \\
\text { film }\end{array}$ & [83] \\
\hline & $\begin{array}{l}\text { phosphorescent Pt- } \\
\text { porphyrin }\end{array}$ & $\mathrm{CO}_{2}$ & Sensors & [84] \\
\hline \multirow[t]{3}{*}{ Agriculture } & $\begin{array}{l}\text { carboxymethyl } \\
\text { chitosan }\end{array}$ & glutathione & & [85] \\
\hline & $\begin{array}{l}\text { attapulgite-NH4HCO3- } \\
\text { glyphosate/amino } \\
\text { silicone oil-poly(vinyl } \\
\text { alcohol) }\end{array}$ & temperature & $\begin{array}{l}\text { core-shell } \\
\text { nanocomposite }\end{array}$ & {$[86]$} \\
\hline & $\begin{array}{l}\text { hydroxypropyl } \\
\text { methylcellulose }\end{array}$ & Environment & Hydrogels & [87] \\
\hline $\begin{array}{l}\text { In-vitro } \\
\text { biomedical } \\
\text { diagnostics }\end{array}$ & $\begin{array}{l}\text { antibody bound } \\
\text { Poly(N- } \\
\text { isopropylacrylamide) }\end{array}$ & biomarkers & $\begin{array}{l}\text { Polymer-coated gold } \\
\text { nanoparticles }\end{array}$ & [88] \\
\hline \multirow[t]{4}{*}{ Sensors } & $\begin{array}{l}\text { poly(N- } \\
\text { isopropylacrylamide) }\end{array}$ & $\begin{array}{l}\text { Temperature } \\
\text { and salt }\end{array}$ & Coated nanoparticle & [89] \\
\hline & $\begin{array}{l}\text { poly(N-(3-amidino)- } \\
\text { aniline) }\end{array}$ & $\mathrm{CO}_{2}$ & Coated nanoparticles & [90] \\
\hline & $\begin{array}{l}\text { chitosan (CHI)/poly } \\
\text { (acrylic acid) }\end{array}$ & Ionic strenght & $\begin{array}{l}\text { coated long-period } \\
\text { gratings }\end{array}$ & [91] \\
\hline & poly(vinyl alcohol) & Glucose & $\begin{array}{l}\text { coated platinum } \\
\text { electrode }\end{array}$ & [92] \\
\hline \multirow[t]{3}{*}{ Drug delivery } & ethycellulose & $\mathrm{pH}$ & $\begin{array}{l}\text { Polymer-coated } \\
\text { insulin-loaded } \\
\text { intestinal patches }\end{array}$ & [93] \\
\hline & $\begin{array}{l}\text { Eudragit }{ }^{\circledR} \text { S100 and } \\
\text { Eudragit }{ }^{\circledR} \text { L100-55 }\end{array}$ & $\mathrm{pH}$ & $\begin{array}{l}\text { Polymer-coated } \\
\text { insulin-loaded } \\
\text { nanoparticles }\end{array}$ & [94] \\
\hline & ethylcellulose & Light & $\begin{array}{l}\text { Polymer-coated } \\
\text { insulin-loaded gold } \\
\text { nanoparticles }\end{array}$ & [95] \\
\hline
\end{tabular}




\begin{tabular}{|l|l|l|l|l|}
\hline & $\begin{array}{l}\text { poly(N- } \\
\text { isopropylacrylamide- } \\
\text { co-N,N- } \\
\text { dimethylacrylamide) }\end{array}$ & temperature & $\begin{array}{l}\text { Core-shell } \\
\text { nanoparticles }\end{array}$ & {$[96]$} \\
\cline { 2 - 5 } & $\begin{array}{l}\text { poly-N- } \\
\text { isopropylacrylamide- } \\
\text { co-itaconic acid }\end{array}$ & $\begin{array}{l}\text { Temperature } \\
\text { and pH }\end{array}$ & $\begin{array}{l}\text { Doxorubicin-loaded } \\
\text { core-shell } \\
\text { nanoparticles }\end{array}$ & {$[97]$} \\
\hline Cosmetics & $\begin{array}{l}\text { polyoxyethylene and } \\
\text { polyoxypropylene }\end{array}$ & temperature & Aqueous composition & {$[98]$} \\
\hline Textile & polyurethanes & temperature & $\begin{array}{l}\text { Polymer coated } \\
\text { shape memory fabric }\end{array}$ & {$[99]$} \\
\hline
\end{tabular}

\section{Conclusion}

. Stimuli-responsive polymers that can be either from natural or synthetic origin react to changes or stimuli such as $\mathrm{pH}$, temperature, light, and so on. Indeed, stimuli are divided into three main categories of physical stimuli, chemical stimuli, and biological stimuli. Thanks to this characteristic, stimuliresponsive polymer offer a vast range of functionality in food, agriculture, drug delivery, biomedical diagnostics, sensors, textile and cosmetics and continue to show great promise. The stimuli responsive materials are divided into four classes of stimuli-responsive polymers, stimuli-responsive nanogel, stimuli-responsive structured particles and stimuli-responsive membrane. The presence of a wide range of polymers with a responsive ability to external stimuli opens the range to a vast array of applications while natural polymers were used in food, agriculture, and drug delivery for human administration, packaging, and microbial and oxidation protection. Synthetic polymers are also used as sensors, scavenging agents and many more applications. Finally, despite the vast knowledge we already have in the topic, more promising findings are being uncovered on yearly basis that can open the doors to a larger niche of applications. 


\section{References}

[1] M. A. Jahid, J. Hu, and H. Zhuo, 'Stimuli-responsive polymers in coating and laminating for functional textile', in Smart Textile Coatings and Laminates, Elsevier, 2019, pp. 155-173.

[2] A. Zhang, K. Jung, A. Li, J. Liu, and C. Boyer, 'Recent advances in stimuli-responsive polymer systems for remotely controlled drug release', Prog. Polym. Sci., vol. 99, p. 101164, Dec. 2019.

[3] I. Galaev, "'Smart" polymers and what they could do in biotechnology and medicine', Trends Biotechnol., vol. 17, no. 8, pp. 335-340, Aug. 1999.

[4] Y. Qiu and K. Park, 'Environment-sensitive hydrogels for drug delivery', Adv. Drug Deliv. Rev., vol. 53, no. 3, pp. 321-339, Dec. 2001.

[5] M. R. Aguilar, C. Elvira, A. Gallardo, B. Vázquez, and J. S. Román, 'Smart Polymers and Their Applications as Biomaterials', Smart Polym., vol. 3, p. 27.

[6] S. J. Grainger and M. E. H. El-Sayed, 'STIMULI-SENSITIVE PARTICLES FOR DRUG DELIVERY', in Biologically-Responsive Hybrid Biomaterials, WORLD SCIENTIFIC, 2010, pp. 171-190.

[7] M. A. C. Stuart et al., 'Emerging applications of stimuli-responsive polymer materials', Nat. Mater., vol. 9, no. 2, pp. 101-113, Feb. 2010.

[8] L. Klouda and A. G. Mikos, 'Thermoresponsive hydrogels in biomedical applications', Eur. J. Pharm. Biopharm., vol. 68, no. 1, pp. 34-45, Jan. 2008.

[9] C.-Y. Chuang, trong-ming Don, and W.-Y. Chiu, 'Synthesis of Chitosan-Based Thermo- and pHResponsive Porous Nanoparticles by Temperature-Dependent Self-Assembly Method and Their Application in Drug Release', J. Polym. Sci. Part Polym. Chem., vol. 47, pp. 5126-5136, Oct. 2009.

[10] M. Fathi, P. SahandiZangabad, S. Majidi, J. Barar, H. Erfan-Niya, and Y. Omidi, 'Stimuli-responsive chitosan-based nanocarriers for cancer therapy', Biolmpacts BI, vol. 7, no. 4, pp. 269-277, 2017.

[11] S. CHATTERJEE and P. Chi-leung HUI, 'Review of Stimuli-Responsive Polymers in Drug Delivery and Textile Application', Molecules, vol. 24, no. 14, Jul. 2019.

[12] E. Cabane, X. Zhang, K. Langowska, C. G. Palivan, and W. Meier, 'Stimuli-Responsive Polymers and Their Applications in Nanomedicine', Biointerphases, vol. 7, no. 1, p. 9, Feb. 2012.

[13] 'Stimuli-responsive polymers: Fundamental considerations and applications | SpringerLink'. [Online]. Available: https://link.springer.com/article/10.1007/s13233-017-5088-7. [Accessed: 06-Dec-2019].

[14] A. Lendlein and V. P. Shastri, 'Stimuli-Sensitive Polymers', Adv. Mater., vol. 22, no. 31, pp. 33443347, 2010.

[15] D. Roy, J. Cambre, and B. Sumerlin, 'Roy D, Cambre JN, Sumerlin BS. Future perspectives and recent advances in stimuli-responsive materials. Prog Polym Sci 35: 278-301', Prog. Polym. Sci., vol. 35, pp. 278-301, Feb. 2010.

[16] H. Almeida, M. H. Amaral, and P. Lobão, 'Temperature and pH stimuli-responsive polymers and their applications in controlled and self- regulated drug delivery', J. Appl. Pharm. Sci., p. 10.

[17] F. Liu and M. Urban, 'Liu, F. \& Urban, M. W. Recent advances and challenges in designing stimuliresponsive polymers. Prog. Polym. Sci. 35, 3', Prog. Polym. Sci., vol. 35, pp. 3-23, Feb. 2010.

[18] P. Bawa, V. Pillay, Y. E. Choonara, and L. C. du Toit, 'Stimuli-responsive polymers and their applications in drug delivery', Biomed. Mater. Bristol Engl., vol. 4, no. 2, p. 022001, Apr. 2009.

[19] J. Kopeček, 'Hydrogel Biomaterials: A Smart Future?', Biomaterials, vol. 28, no. 34, pp. 51855192, Dec. 2007.

[20] S. Kim, J.-H. Kim, O. Jeon, I. C. Kwon, and K. Park, 'Engineered Polymers for Advanced Drug Delivery', Eur. J. Pharm. Biopharm. Off. J. Arbeitsgemeinschaft Pharm. Verfahrenstechnik EV, vol. 71, no. 3, pp. 420-430, Mar. 2009.

[21] A. Kumar, A. Srivastava, I. Galaev, and B. Mattiasson, 'Smart polymers: Physical forms and bioengineering applications', Prog. Polym. Sci., vol. 32, pp. 1205-1237, Oct. 2007.

[22] D. Kuckling, 'Stimuli-Responsive Gels', Gels, vol. 4, no. 3, p. 60, Sep. 2018.

[23] A. Raza, T. Rasheed, F. Nabeel, U. Hayat, M. Bilal, and H. M. N. Iqbal, 'Endogenous and Exogenous Stimuli-Responsive Drug Delivery Systems for Programmed Site-Specific Release', Molecules, vol. 24, no. 6, Mar. 2019. 
[24] 'Shape memory fibers prepared via wet, reaction, dry, melt, and electro spinning - diagram, schematic, and image $01^{\prime}$. [Online]. Available:

http://www.patentsencyclopedia.com/imgfull/20090093606_01. [Accessed: 06-Dec-2019].

[25] M. A. Jahid, J. Hu, and H. Zhuo, ' 6 - Stimuli-responsive polymers in coating and laminating for functional textile', in Smart Textile Coatings and Laminates (Second Edition), W. C. Smith, Ed. Woodhead Publishing, 2019, pp. 155-173.

[26] M. Motornov, Y. Roiter, I. Tokarev, and S. Minko, 'Stimuli-responsive nanoparticles, nanogels and capsules for integrated multifunctional intelligent systems', Prog. Polym. Sci., vol. 35, no. 12, pp. 174-211, Jan. 2010.

[27] Z. Jiang, J. Chen, L. Cui, X. Zhuang, J. Ding, and X. Chen, 'Advances in Stimuli-Responsive Polypeptide Nanogels', Small Methods, vol. 2, no. 3, p. 1700307, Mar. 2018.

[28] M. Vicario-de-la-Torre and J. Forcada, 'The Potential of Stimuli-Responsive Nanogels in Drug and Active Molecule Delivery for Targeted Therapy', Gels, vol. 3, no. 2, p. 16, 2017.

[29] K. Madhusudana Rao, K. S. V. Krishna Rao, and C.-S. Ha, 'Functional stimuli-responsive polymeric network nanogels as cargo systems for targeted drug delivery and gene delivery in cancer cells', in Design of Nanostructures for Theranostics Applications, vol. 64, no. 9, Elsevier, 2018, pp. 243275.

[30] J. Ryu, R. T. Chacko, S. Jiwpanich, S. Bickerton, R. P. Babu, and S. Thayumanavan, 'Self-CrossLinked Polymer Nanogels: A Versatile Nanoscopic Drug Delivery Platform', J. Am. Chem. Soc., vol. 132, no. 48, pp. 17227-17235, Dec. 2010.

[31] K. Madhusudana Rao, K. S. V. Krishna Rao, and C. S. Ha, Functional stimuli-responsive polymeric network nanogels as cargo systems for targeted drug delivery and gene delivery in cancer cells. Elsevier Inc., 2018.

[32] S. Jin, D. Li, P. Yang, J. Guo, J. Q. Lu, and C. Wang, 'Redox/pH stimuli-responsive biodegradable PEGylated P(MAA/BACy) nanohydrogels for controlled releasing of anticancer drugs', Colloids Surf. Physicochem. Eng. Asp., vol. 484, pp. 47-55, 2015.

[33] S. Jinet al., 'Biodegradation and Toxicity of Protease/Redox/pH Stimuli-Responsive PEGlated PMAA Nanohydrogels for Targeting Drug delivery', ACS Appl. Mater. Interfaces, vol. 7, no. 35, pp. 19843-19852, 2015.

[34] W. Richtering and A. Pich, 'The special behaviours of responsive core-shell nanogels', Soft Matter, vol. 8, no. 45, pp. 11423-11430, 2012.

[35] J. K. Oh, C. Tang, H. Gao, N. V. Tsarevsky, and K. Matyjaszewski, 'Inverse Miniemulsion ATRP: A New Method for Synthesis and Functionalization of Well-Defined Water-Soluble/Cross-Linked Polymeric Particles', J. Am. Chem. Soc., vol. 128, no. 16, pp. 5578-5584, Apr. 2006.

[36] S. Hajebiet al., 'Stimulus-responsive polymeric nanogels as smart drug delivery systems', Acta Biomater., vol. 92, pp. 1-18, 2019.

[37] S. I. Sawada, H. Yukawa, S. Takeda, Y. Sasaki, and K. Akiyoshi, 'Self-assembled nanogel of cholesterol-bearing xyloglucan as a drug delivery nanocarrier', J. Biomater. Sci. Polym. Ed., vol. 28, no. 10-12, pp. 1183-1198, 2017.

[38] Y. Sasaki and K. Akiyoshi, 'Nanogel engineering for new nanobiomaterials: from chaperoning engineering to biomedical applications', Chem. Rec., p. n/a-n/a, Sep. 2010.

[39] W.-C. Yang, R. Xie, X.-Q. Pang, X.-J. Ju, and L.-Y. Chu, 'Preparation and characterization of dual stimuli-responsive microcapsules with a superparamagnetic porous membrane and thermoresponsive gates', J. Membr. Sci., vol. 321, no. 2, pp. 324-330, Aug. 2008.

[40] A. J. Brown et al., 'Interfacial microfluidic processing of metal-organic framework hollow fiber membranes', Science, vol. 345, no. 6192, pp. 72-75, Jul. 2014.

[41] S.-C. Low and Q.-H. Ng, 'Chapter 4 - Progress of stimuli responsive membranes in water treatment', in Advanced Nanomaterials for Membrane Synthesis and its Applications, W.-J. Lau, A. F. Ismail, A. Isloor, and A. Al-Ahmed, Eds. Elsevier, 2019, pp. 69-99.

[42] D. Wandera, S. R. Wickramasinghe, and S. M. Husson, 'Stimuli-responsive membranes', J. Membr. Sci., vol. 357, no. 1-2, pp. 6-35, Jul. 2010. 
[43] S. M. Husson, 'Synthesis Aspects in the Design of Responsive Membranes', in Responsive Membranes and Materials, John Wiley \& Sons, Ltd, 2012, pp. 73-96.

[44] B. Ma et al., 'Facile Fabrication of Composite Membranes with Dual Thermo- and pH-Responsive Characteristics', ACS Appl. Mater. Interfaces, vol. 9, no. 16, pp. 14409-14421, Apr. 2017.

[45] R. Singh and N. Hankins, Emerging Membrane Technology for Sustainable Water Treatment. Elsevier, 2016.

[46] G. Kocak, C. Tuncer, and V. Bütün, 'pH-Responsive polymers', Polym. Chem., vol. 8, no. 1, pp. 144-176, Dec. 2016.

[47] D. Schmaljohann, 'Thermo- and pH-responsive polymers in drug delivery', Adv. Drug Deliv. Rev., vol. 58, no. 15, pp. 1655-1670, Dec. 2006.

[48] S. Dai, P. Ravi, and K. C. Tam, 'pH-Responsive polymers: synthesis, properties and applications', Soft Matter, vol. 4, no. 3, pp. 435-449, Feb. 2008.

[49] J. Hu, G. Zhang, Z. Ge, and S. Liu, 'Stimuli-responsive tertiary amine methacrylate-based block copolymers: Synthesis, supramolecular self-assembly and functional applications', Prog. Polym. Sci., vol. 39, no. 6, pp. 1096-1143, Jun. 2014.

[50] A. Moreno, J. C. Ronda, V. Cádiz, M. Galià, G. Lligadas, and V. Percec, 'pH-Responsive Micellar Nanoassemblies from Water-Soluble Telechelic Homopolymers Endcoding Acid-Labile MiddleChain Groups in Their Hydrophobic Sequence-Defined Initiator Residue', ACS Macro Lett., vol. 8, no. 9, pp. 1200-1208, Sep. 2019.

[51] 'Pharmaceutical significance of Eudragit: A review'.

[52] T. Sim et al., 'A pH-Sensitive Polymer for Cancer Targeting Prepared by One-Step Modulation of Functional Side Groups', Macromol. Res., vol. 27, no. 8, pp. 795-802, Aug. 2019.

[53] D. J. Peeler, S. N. Thai, Y. Cheng, P. J. Horner, D. L. Sellers, and S. H. Pun, 'pH-sensitive polymer micelles provide selective and potentiated lytic capacity to venom peptides for effective intracellular delivery', Biomaterials, vol. 192, pp. 235-244, 2019.

[54] J. M. Benns, J. S. Choi, R. I. Mahato, J. S. Park, and S. W. Kim, 'pH-sensitive cationic polymer gene delivery vehicle: N-Ac-poly(L-histidine)-graft-poly(L-lysine) comb shaped polymer', Bioconjug. Chem., vol. 11, no. 5, pp. 637-645, Oct. 2000.

[55] H. S. Lim, D. Kwak, D. Y. Lee, S. G. Lee, and K. Cho, 'UV-Driven Reversible Switching of a Roselike Vanadium Oxide Film between Superhydrophobicity and Superhydrophilicity', J. Am. Chem. Soc., vol. 129, no. 14, pp. 4128-4129, Apr. 2007.

[56] J. Cui and A. Del Campo, 'Photo-responsive polymers: properties, synthesis and applications', in Smart Polymers and their Applications, no. i, Elsevier, 2014, pp. 93-133.

[57] B. L. Feringa, R. a Van Delden, N. Koumura, and E. M. Geertsema, 'Chiroptical Molecular Switches Chiroptical Molecular Switches', Chem. Rev., vol. 3, pp. 123-163, 2000.

[58] T. Ikeda, J. I. Mamiya, and Y. Yu, 'Photomechanics of liquid-crystalline elastomers and other polymers', Angew. Chem. - Int. Ed., vol. 46, no. 4, pp. 506-528, 2007.

[59] S. Samanta and J. Locklin, 'Formation of photochromic spiropyran polymer brushes via surfaceinitiated, ring-opening metathesis polymerization: Reversible photocontrol of wetting behavior and solvent dependent morphology changes', Langmuir, vol. 24, no. 17, pp. 9558-9565, 2008.

[60] M. Nagel et al., 'Aryltriazene photopolymer thin films as sacrificial release layers for laserassisted forward transfer systems: Study of photoablative decomposition and transfer behavior', Appl. Phys. Mater. Sci. Process., vol. 92, no. 4, pp. 781-789, 2008.

[61] A. Doraiswamyet al., 'Excimer laser forward transfer of mammalian cells using a novel triazene absorbing layer', Appl. Surf. Sci., vol. 252, no. 13, pp. 4743-4747, Apr. 2006.

[62] W. Ji et al., 'Coumarin-containing photo-responsive nanocomposites for NIR light-triggered controlled drug release via a two-photon process', J. Mater. Chem. B, vol. 1, no. 43, pp. 59425949, 2013.

[63] M. Zelzer and R. V. Ulijn, 'Enzyme-responsive polymers: properties, synthesis and applications', in Smart Polymers and their Applications, Elsevier, 2014, pp. 166-203.

[64] A. Nelson, 'Engineering interactions', Nat. Mater., vol. 7, no. 7, pp. 523-525, Jul. 2008. 
[65] C. Alexander and K. M. Shakesheff, 'Responsive polymers at the biology/materials science interface', Adv. Mater., vol. 18, no. 24, pp. 3321-3328, 2006.

[66] C. Sun et al., 'A ROS-responsive polymeric micelle with a $\pi$-conjugated thioketal moiety for enhanced drug loading and efficient drug delivery', Org. Biomol. Chem., vol. 15, no. 43, pp. 9176-9185, 2017.

[67] S. Uthaman, K. M. Huh, and I.-K. Park, 'Tumor microenvironment-responsive nanoparticles for cancer theragnostic applications', Biomater. Res., vol. 22, no. 1, p. 22, Dec. 2018.

[68] J. Huang, Q. Shu, L. Wang, H. Wu, A. Y. Wang, and H. Mao, 'Layer-by-layer assembled milk protein coated magnetic nanoparticle enabled oral drug delivery with high stability in stomach and enzyme-responsive release in small intestine', Biomaterials, vol. 39, pp. 105-113, 2015.

[69] M. Maier et al., 'Highly site specific, protease cleavable, hydrophobic peptide-polymer nanoparticles', Macromolecules, vol. 44, no. 16, pp. 6258-6267, 2011.

[70] H. Koga et al., 'Fluorescent nanoparticles consisting of lipopeptides and fluorescein-modified polyanions for monitoring of protein kinase activity', Bioconjug. Chem., vol. 22, no. 8, pp. 15261534, 2011.

[71] M. J. Kratochvil, T. Yang, H. E. Blackwell, and D. M. Lynn, 'Nonwoven Polymer Nanofiber Coatings That Inhibit Quorum Sensing in Staphylococcus aureus: Toward New Nonbactericidal Approaches to Infection Control', ACS Infect. Dis., vol. 3, no. 4, pp. 271-280, 2017.

[72] J. Zhou, A. L. Loftus, G. Mulley, and A. T. A. Jenkins, 'A Thin Film Detection/Response System for Pathogenic Bacteria', J. Am. Chem. Soc., vol. 132, no. 18, pp. 6566-6570, May 2010.

[73] A. K. Bajpai, S. K. Shukla, S. Bhanu, and S. Kankane, 'Responsive polymers in controlled drug delivery', Prog. Polym. Sci., vol. 33, no. 11, pp. 1088-1118, Nov. 2008.

[74] S. R. MacEwan, D. J. Callahan, and A. Chilkoti, 'Stimulus-responsive macromolecules and nanoparticles for cancer drug delivery', Nanomed., vol. 5, no. 5, pp. 793-806, Jul. 2010.

[75] P. Zarrintajet al., 'Thermo-sensitive polymers in medicine: A review', Eur. Polym. J., vol. 117, pp. 402-423, Aug. 2019.

[76] D. Roy, J. N. Cambre, and B. S. Sumerlin, 'Future perspectives and recent advances in stimuliresponsive materials', Prog. Polym. Sci. Oxf., vol. 35, no. 1-2, pp. 278-301, 2010.

[77] G. Filipcsei, J. Fehér, and M. Zrínyi, 'Electric field sensitive neutral polymer gels', J. Mol. Struct., vol. 554, no. 1, pp. 109-117, 2000.

[78] E. A. Moschou, S. F. Peteu, L. G. Bachas, M. J. Madou, and S. Daunert, 'Artificial muscle material with fast electroactuation under neutral pH conditions', Chem. Mater., vol. 16, no. 12, pp. 24992502, 2004.

[79] S. Kagatani, T. Shinoda, Y. Konno, M. Fukui, T. Ohmura, and Y. Osada, 'Electroresponsive pulsatile depot delivery of insulin from poly(dimethylammopropylacrylamide) gel in rats', J. Pharm. Sci., vol. 86, no. 11, pp. 1273-1277, 1997.

[80] H. J. Joung, M.-J. Choi, J. T. Kim, S. H. Park, H. J. Park, and G. H. Shin, 'Development of FoodGrade Curcumin Nanoemulsion and its Potential Application to Food Beverage System:

Antioxidant Property and In Vitro Digestion', J. Food Sci., vol. 81, no. 3, pp. N745-753, Mar. 2016.

[81] H. Liu, C. Wang, S. Zou, Z. Wei, and Z. Tong, 'Simple, Reversible Emulsion System Switched by pH on the Basis of Chitosan without Any Hydrophobic Modification', Langmuir, vol. 28, no. 30, pp. 11017-11024, Jul. 2012.

[82] B. Kuswandi, Jayus, A. Restyana, A. Abdullah, L. Y. Heng, and M. Ahmad, 'A novel colorimetric food package label for fish spoilage based on polyaniline film', Food Control, vol. 25, no. 1, pp. 184-189, May 2012.

[83] Essential Oils in Food Preservation, Flavor and Safety. Elsevier, 2016.

[84] N. B. Borchert, J. P. Kerry, and D. B. Papkovsky, 'A CO2 sensor based on Pt-porphyrin dye and FRET scheme for food packaging applications', Sens. Actuators B Chem., vol. 176, pp. 157-165, Jan. 2013.

[85]Z. Yu et al., 'Glutathione-Responsive Carboxymethyl Chitosan Nanoparticles for Controlled Release of Herbicides', Mater. Sci. Appl., vol. 06, no. 06, pp. 591-604, 2015. 
[86] Y. Chi, G. Zhang, Y. Xiang, D. Cai, and Z. Wu, 'Fabrication of a Temperature-Controlled-Release Herbicide Using a Nanocomposite', ACS Sustain. Chem. Eng., vol. 5, no. 6, pp. 4969-4975, Jun. 2017.

[87] Y.-C. Chen and Y.-H. Chen, 'Thermo and pH-responsive methylcellulose and hydroxypropyl methylcellulose hydrogels containing $\mathrm{K} 2 \mathrm{SO} 4$ for water retention and a controlled-release watersoluble fertilizer', Sci. Total Environ., vol. 655, pp. 958-967, Mar. 2019.

[88] A. S. Hoffman, 'Stimuli-responsive polymers: Biomedical applications and challenges for clinical translation', Adv. Drug Deliv. Rev., vol. 65, no. 1, pp. 10-16, Jan. 2013.

[89] S. Maji, B. Cesur, Z. Zhang, B. G. De Geest, and R. Hoogenboom, 'Poly(N-isopropylacrylamide) coated gold nanoparticles as colourimetric temperature and salt sensors', Polym. Chem., vol. 7, no. 9, pp. 1705-1710, 2016.

[90] Y. Ma, K. Promthaveepong, and N. Li, 'CO2-Responsive Polymer-Functionalized Au Nanoparticles for CO2 Sensor', Anal. Chem., vol. 88, no. 16, pp. 8289-8293, Aug. 2016.

[91] F. Yang, S. Sukhishvili, H. Du, and F. Tian, 'Marine salinity sensing using long-period fiber gratings enabled by stimuli-responsive polyelectrolyte multilayers', Sens. Actuators B Chem., vol. 253, pp. 745-751, 2017.

[92] A. Kikuchi et al., 'Glucose-sensing electrode coated with polymer complex gel containing phenylboronic Acid', Anal. Chem., vol. 68, no. 5, pp. 823-828, Mar. 1996.

[93] K. Whitehead, Z. Shen, and S. Mitragotri, 'Oral delivery of macromolecules using intestinal patches: Applications for insulin delivery', J. Controlled Release, vol. 98, no. 1, pp. 37-45, 2004.

[94] K. Sonajeet al., 'Enteric-coated capsules filled with freeze-dried chitosan/poly( $\gamma$-glutamic acid) nanoparticles for oral insulin delivery', Biomaterials, vol. 31, no. 12, pp. 3384-3394, 2010.

[95] B. P. Timko et al., 'Near-infrared-actuated devices for remotely controlled drug delivery', Proc. Natl. Acad. Sci. U. S. A., vol. 111, no. 4, pp. 1349-1354, 2014.

[96] J. L. Zhang, R. S. Srivastava, and R. D. K. Misra, 'Core-shell magnetite nanoparticles surface encapsulated with smart stimuli-responsive polymer: Synthesis, characterization, and LCST of viable drug-targeting delivery system', Langmuir, vol. 23, no. 11, pp. 6342-6351, 2007.

[97] M. Ghorbani, H. Hamishehkar, N. Arsalani, and A. A. Entezami, 'Preparation of thermo and pHresponsive polymer@Au/Fe<inf $>3</$ inf $>0<$ inf $>4</$ inf $>$ core/shell nanoparticles as a carrier for delivery of anticancer agent', J. Nanoparticle Res., vol. 17, no. 7, 2015.

[98] R. Y. Lochhead, 'The Role of Polymers in Cosmetics: Recent Trends', in Cosmetic Nanotechnology, vol. 961, S. E. Morgan, K. O. Havelka, and R. Y. Lochhead, Eds. Washington, DC: American Chemical Society, 2007, pp. 3-56.

[99] S. Mondal and J. L. Hu, 'Water vapor permeability of cotton fabrics coated with shape memory polyurethane', Carbohydr. Polym., vol. 67, no. 3, pp. 282-287, Feb. 2007.

[100] S. Talegaonkar, H. Sharma, S. Pandey, P. K. Mishra, and R. Wimmer, '3 - Bionanocomposites: smart biodegradable packaging material for food preservation', in Food Packaging, A. M.

Grumezescu, Ed. Academic Press, 2017, pp. 79-110.

[101] J. Guo and G. Kaletunç, 'Dissolution kinetics of $\mathrm{pH}$ responsive alginate-pectin hydrogel particles', Food Res. Int. Ott. Ont, vol. 88, no. Pt A, pp. 129-139, Oct. 2016.

[102] Y. Ma et al., 'Biobased polymeric surfactant: Natural glycyrrhizic acid-appended homopolymer with multiple pH-responsiveness', J. Colloid Interface Sci., vol. 541, pp. 93-100, Apr. 2019.

[103] D. Restucciaet al., 'New EU regulation aspects and global market of active and intelligent packaging for food industry applications', Food Control, vol. 21, no. 11, pp. 1425-1435, Nov. 2010.

[104] M. Ghaani, C. A. Cozzolino, G. Castelli, and S. Farris, 'An overview of the intelligent packaging technologies in the food sector', Trends Food Sci. Technol., vol. 51, pp. 1-11, May 2016.

[105] J. Kerry and D. Papkovsky, 'Development and use of non-destructive, continuous assessment, chemical oxygen sensors in packs containing sensitive foodstuffs', Res. Adv. Food Sci., vol. 3, pp. 121-140, Jan. 2002. 
[106] S. Cichosz, A. Masek, and M. Zaborski, 'Polymer-based sensors: A review', Polym. Test., vol. 67, pp. 342-348, May 2018.

[107] A. Antonacci, F. Arduini, D. Moscone, G. Palleschi, and V. Scognamiglio, 'Nanostructured (Bio)sensors for smart agriculture', TrAC Trends Anal. Chem., vol. 98, pp. 95-103, Jan. 2018.

[108] H. Guo, J. C. White, Z. Wang, and B. Xing, 'Nano-enabled fertilizers to control the release and use efficiency of nutrients', Curr. Opin. Environ. Sci. Health, vol. 6, pp. 77-83, Dec. 2018.

[109] A. Singh et al., 'Advances in controlled release pesticide formulations: Prospects to safer integrated pest management and sustainable agriculture', J. Hazard. Mater., p. 121525, Nov. 2019.

[110] G. Liu et al., 'Hydrazone-linked soybean protein isolate-carboxymethyl cellulose conjugates for pH-responsive controlled release of pesticides', Polym. J., vol. 51, no. 11, pp. 1211-1222, Nov. 2019.

[111] A. S. Hoffman, 'Stimuli-responsive polymers: Biomedical applications and challenges for clinical translation', Adv. Drug Deliv. Rev., vol. 65, no. 1, pp. 10-16, 2013.

[112] J. Yu, Y. Zhang, H. Bomba, and Z. Gu, 'Stimuli-responsive delivery of therapeutics for diabetes treatment', Bioeng. Transl. Med., vol. 1, no. 3, pp. 323-337, 2016.

[113] V. Ruiz-Valdepeñas Montiel, J. R. Sempionatto, S. Campuzano, J. M. Pingarrón, B. Esteban Fernández de Ávila, and J. Wang, 'Direct electrochemical biosensing in gastrointestinal fluids', Anal. Bioanal. Chem., vol. 411, no. 19, pp. 4597-4604, Jul. 2019.

[114] M. Wei, Y. Gao, X. Li, and M. J. Serpe, 'Stimuli-responsive polymers and their applications', Polym. Chem., vol. 8, no. 1, pp. 127-143, Dec. 2016.

[115] K. Singha, 'A Review on Coating \& Lamination in Textiles: Processes and Applications', Am. J. Polym. Sci., vol. 2, no. 3, pp. 39-49, 2012.

[116] X. Ding and J. Hu, 'Temperature-sensitive polyurethane properties', 2003.

[117] S. Mondal, J. L. Hu, and Z. Yong, 'Free volume and water vapor permeability of dense segmented polyurethane membrane', J. Membr. Sci., vol. 280, no. 1-2, pp. 427-432, Sep. 2006.

[118] P.-C. Hsu et al., 'Radiative human body cooling by nanoporous polyethylene textile', Science, vol. 353, no. 6303, pp. 1019-1023, Sep. 2016. 
